\title{
ESTUDOS
}

IBERO-AMERICANOS

\section{Vida cotidiana y dictadura militar en la Argentina: un balance historiográfico*}

\author{
Vida cotidiana e ditadura militar na Argentina: um balanço historiográfico \\ Daily life and military dictatorship in Argentina: a historiographical balance
}

Daniel Lvovich**

\begin{abstract}
Resumen: En este artículo trazamos un balance historiográfico acerca del campo de los estudios acerca de la vida cotidiana durante la última dictadura militar que gobernó la Argentina entre 1976 y 1983.Para ello intentamos en primer término dar cuenta de los debates fundamentales en las historiografías nacionales que han transitado con más profundidad estas problemáticas, para abordar luego el caso argentino, considerando las principales producciones y los contextos académicos y políticos en que emergieron.
\end{abstract}

Palabras clave: Historiografía; Vida cotidiana; Dictadura.

Resumo: Neste artigo, fizemos um balanço historiográfico sobre o campo de estudos sobre a vida cotidiana durante a ditadura militar que governou a Argentina entre 1976 e 1983. Tentamos em primeiro lugar explicar os debates fundamentais em historiografias nacionais que trataram com mais profundidade estas questões, em seguida, para abordar o caso argentino, considerando as principais produções e contextos académicos e políticos em que surgiram.

Palavras-chave: Historiografia; Vida cotidiana; Ditadura.

\begin{abstract}
In this article we draw a historiographical balance on the field of studies on everyday life during the military dictatorship that ruled Argentina between 1976 and 1983. Primarily we try to account for the fundamental debates in national historiographies that have traveled in more depth these issues, then take the Argentine case, considering the main productions and academic and political contexts in which they emerged.
\end{abstract}

Keywords: Historiography; Everyday life; Dictatorship.

\footnotetext{
*Este artículo se desarrolla en el marco del PICT 2013 "Desafíos historiográficos, teóricos y didácticos dela bordaje del pasado reciente en Argentina" de la Agencia Nacional de Investigaciones Científicas y Tecnológicas.

** Investigador de la Universidad Nacional de General Sarmiento y del Consejo Nacional de Investigaciones Científicas y Técnicas de la Argentina. Doctor en Historia por la Universidad Nacional de La Plata.

dados biográficos_biographic data
} 
El propósito de este artículo es trazar un balance historiográfico acerca de un campo aún incipiente, pero que despierta un creciente interés: el de los estudios acerca de la vida cotidiana durante la última dictadura militar que gobernó la Argentina entre 1976 y 1983. No es posible plantearse el interrogante sobre los vínculos entre la sociedad y la dictadura militar, o el ciclo de violencias que la antecedió. sin preguntarse cómo, y a través de qué procesos, vehículos y dispositivos se produce el encuentro con la dimensión violenta del poder y la resistencia. Ese fue el camino emprendido, con resultados diversos, por diversas investigaciones. A la vez, para comprender los modos de formular estos interrogantes es imprescindible remitirse, aun de modo somero, a los contextos historiográficos y políticos en los que emergieron esas producciones.

La dimensión de lo cotidiano atraviesa un horizonte muy amplio de prácticas que organizan la vida doméstica, y ha recibido en los últimos años una creciente atención por parte de distintas historiografías nacionales, aunque el significado de dicha expresión dista de ser unánime, ya que hasta el mismo concepto remite a diversas significaciones en la práctica historiográfica. Al respecto, en 1991 Peter Burke señalaba que aunque la expresión vida cotidiana circulaba desde hacía decenios, el interés de la historiografía en el fenómeno se había desplegado desde fines de la década de 1960, en contraste con el rechazo a su indagación previa, por habérselo considerado hasta entonces un tema trivial. El propio Burke señalaba que se trata de un abordaje con problemas para ser definido con precisión, pero que comparte con la "historia desde abajo" y la "historia de la cultura popular" "el interés por el mundo de la experiencia ordinaria (más que por la sociedad en abstracto) en cuanto punto de partida, junto con un empeño por considerar problemática la vida diaria..." (BURKE, 1996, p. 24-25) Se trata así de un abordaje centrado en la experiencia cotidiana de los sectores populares, en una mirada que se emparenta con la rica tradición de estudios de la clase obrera y la cultura popular del marxismo británico. (WALTON, 1995) Como veremos, para otras tradiciones la indagación no se restringe a la experiencia popular sino que abarca también la propia de las elites sociales.

La noción de vida cotidiana resulta un concepto de empalme entre los niveles macro y microsociales, tanto en términos estructurales cuanto en lo referente a la percepción de los actores. Así, en su clásico libro Agnes Heller define la vida cotidiana "como el conjunto de actividades que caracterizan la reproducción de los hombres particulares, los cuales a su vez, crean las posibilidades de reproducción social" (HELLER, 1987, p. 19). Por su lado, Norbert Lechner sostiene que la esfera de la vida cotidiana es aquella en la que se desarrolla la producción y reproducción de certezas básicas con que evaluamos lo novedoso y lo problemático, y la sede en que se plantea la vivencia subjetiva de las condiciones estructurales. Como consecuencia, el académico chileno afirma que en la práctica de investigación “... el estudio del cambio social requiere investigaciones sobre aquellas modificaciones moleculares, casi imperceptibles y que, sin embargo, van cambiando justamente esas nociones de lo normal y natural a partir de las cuales juzgamos lo que son rupturas". (LECHNER, 1988, p. 45)

Es muy probable que sea la corriente alemana de historia de la vida cotidiana, la Alltagsgechichte, la que haya creado los instrumentos más sofisticados para intentar captar los distintos elementos que constituyen la historicidad de las prácticas de las multitudes, abordando tanto la experiencia popular cuanto la de las elites. Como ha expresado Alf Lütdke, la apuesta de esta corriente reside en captar "las formas en que los hombres se apropian de las condiciones en las que viven, producen experiencias, utilizan modos de expresión e interpretaciones". En este proceso los agentes se convierten en actores que "interpretan y se muestran, presionan o rechazan". (LÜDTKE, 1995, p. 49). Estas perspectivas se articulan sin dificultad con el énfasis de Michel De Certeau, en la capacidad de resignificación de los sujetos "ordinarios" en su cotidianeidad. (DE CERTEAU, 2000, p. XVII-XVIII)

Pensados desde una sensibilidad que buscaba encontrar las resistencias obreras y populares al nazismo que otras indagaciones no habían hallado, buena parte de los trabajos de esta corriente dieron cuenta, sin embargo, múltiples expresiones de conformismo - si no de adhesión a dicho régimen - en los testimonios recogidos en las diversas investigaciones desarrolladas. La inspiración de la corriente surge de las dificultades para conciliar, en la década de 1970, las experiencias individuales con el relato hegemónico sobre el Tercer Reich. Dos grandes proyectos bucearon en la experiencia subjetiva de la vida cotidiana durante el nazismo, haciendo de la historia oral una herramienta privilegiada. El Proyecto Baviera estudió tanto a trabajadores y campesinos como a nobles, magistrados y profesionales, mientras el Proyecto Rhur se concentraba en la experiencia de obreros y empleados (BROSZAT et al., 1977-1983; NIETHAMMER, 1983-1985). Su aporte permitió 
comprender al nazismo como un régimen policrático, y mostró los límites del encuadramiento nazi, al exhibir la desafección, las quejas y hasta la oposición de la población. Sin embargo, las investigaciones mostraron las dificultades para establecer los límites entre los desafectos y los que apoyaban al régimen, mostrando que en la mayor parte de los casos, la conformidad y la no conformidad coexistieron. Estas investigaciones permitieron llegar a la conclusión que la vida cotidiana en el III Reich fue normal, una normalidad que se refleja en las percepciones y memorias, y que muestran que la vida cotidiana no era muy distinta en la República de Weimar, el Tercer Reich y la Republica Federal. (KERSHAW, 2004, cap. 9)

Las críticas que recibieron los aportes de la Alltagsgechichte, resultan pertinentes para cualquier intento de pensar la cotidianeidad en perspectiva histórica. La principal de estas observaciones reside en señalar el riesgo de la desvinculación entre la lógica de los individuos y los pequeños grupos respecto al contexto mayor. Capturando sus sentidos en una escala muy pequeña, el riesgo de no considerar adecuadamente el contexto político e ideológico en que se desarrollaron las vidas de estos sujetos puede llevar a una perspectiva unilateral. Dado que la vida cotidiana no se hace solo desde abajo, ya que es también un producto de condiciones estructurales, políticas, sociales, y otras; para dar cuenta de esta dimensión se deben considerar los modos en que el nazismo politizó lo privado al ampliar enormemente las áreas de injerencia del Estado, y se debe por tanto prestar atención a la transformación de la subjetividad durante ese régimen, cuando lo criminal se tornó normal. Vinculada a esta crítica se pueden considerar las observaciones basadas en significativos aportes empíricos y teóricos, y que dan cuenta de las dificultades para separar con claridad lo público y lo privado, en particular en condiciones de dictadura. ${ }^{1}$

Al respecto, para el caso argentino se ha observado con acierto que mientras el discurso oficial del régimen dictatorial generó la ilusión del país como un ámbito cerrado que debía ser protegido de la penetración, esta ilusión “... ocultaba la apertura de todas las instituciones a la invasión y transformación por parte del Estado" (FILC, 1997, p. 38). Mientras el Estado fue definido como el guardián de la nación, el espacio privado fue caracterizado como el único espacio seguro, y en particular la familia resultó definida como el lugar

\footnotetext{
1 Para un ejemplo de este tipo de sensibilidad y de un modo sofisticado de tratamiento delas fuentes orales ver PASSERINI, 1987; ELEY, 1989; SAZ, 2004.
}

privilegiado para la formación de argentinos acordes a la "esencia nacional" postulada por el régimen. Sin embargo, dado que el Estado podía juzgar la moral de los ciudadanos y cualquier comportamiento podía ser calificada de moral o inmoral “... todas las prácticas en el espacio privado quedaban bajo el control estatal, siendo así politizadas". De tal modo, el discurso autoritario "transformó una vez más lo privado en político y lo político en privado" (FILC, 1997, p. 37-40)

Otra crítica importante a la tradición alemana de estudios de la vida cotidiana se extiende en realidad a buena parte de la historia oral, ya que se refiere no solo a las transformaciones en las narraciones que conllevan los cambios en los regímenes de memoria, sino también a las posibilidades de manipulación, ya que en los testimonios se puede omitir voluntariamente, justificar, racionalizar, etc. (NOLAN, 1988).

Como veremos, la producción argentina resultó relativamente ajena a estos debates teóricos y metodológicos, produciéndose una serie de trabajos a lo largo de más de dos décadas que, a nuestro entender, no abordan de manera siempre totalmente solvente el problema de la articulación entre los niveles macro y micro y las dimensiones de lo público y lo privado.

\section{Los estudios pioneros sobre vida cotidiana y dictadura en Argentina}

En el caso argentino, aunque no se ha desarrollado una reflexión teórica sistemática ni una discusión pública del concepto, la preocupación por la historia de la vida cotidiana ha nacido de manera casi simultánea con la preocupación de las ciencias sociales por investigar el fenómeno dictatorial, y no son pocos los trabajos que -en busca fundamentalmente de dar cuenta de las actitudes sociales y de las transformaciones en las características del lazo social- han intentado dar cuenta de esta cuestión con el cambio del milenio.

Desde comienzos de la década de 1980, con la dictadura militar aun en el poder, encontramos las primeras miradas en las que está presente el interrogante por al modo en que el terror estatal impactó en la cotidianeidad social. Probablemente el primer trabajo que abordó esta temática haya sido el que Juan Corradi dedicó al análisis del terror como modo clave para la comprensión de la dictadura argentina. Aunque el terror provenía desde arriba, como producto del propósito de los grupos dominantes de dar prioridad al restablecimiento del monopolio de la coerción, los grupos subordinados, y en particular los sectores 
medios también manifestaron "una demanda primitiva de orden y una disposición generalizada a suscribir un pacto hobessiano" (CORRADI, 1996, p. 89). Corradi da cuenta de este modo de un elemento que reaparecería en los sucesivos trabajos que abordaron la problemática de la vida cotidiana bajo el régimen militar: para los actores, hay una cisura temporal entre el gobierno de Isabel Perón caracterizado como un momento de caos y la violencia; y el régimen dictatorial visualizado - al menos en el momento de su implantación- como un período de orden y relativa tranquilidad. El régimen de terror, según Corradi no solo resulto productor de unos sujetos políticos que obedecían "absoluta pero voluntariamente", sino que logró a una escala microsocial que todos tendieran “... a tomar conciencia de la importancia de la seguridad, y metabolizaban en el microcosmos del vecindario, del trabajo o en la intimidad de la vida familiar, la embestida brutal proveniente de arriba" Ello no dejó de tener consecuencias en la modalidad del lazo social:

La combinación de la intemporalidad del terror y la alta velocidad del dinero, la abstracción desorientadora de los procesos políticos y económicos explican porque las convenciones sociales tradicionales como el compañerismo y la convivencia civil cedieron ante el cinismo penetrante que no siquiera el tratamiento psíquico puede cambiar" (CORRADI, 1996, p. 103)

Estas conclusiones de Corradi, resultado de su rol como testigo del proceso más que del -por otra parte imposible - uso de instrumentos controlados de recolección de datos, resultan de un amplísimo nivel de generalidad, de modo que no permiten distinguir el indudable impacto del terror en los distintos grupos sociales, realidades regionales, $\mathrm{u}$ otras variables. ${ }^{2} \mathrm{Sin}$ embargo, inaugura una mirada destinada a perdurar,

\footnotetext{
2 Corradi basa una parte de su análisis y cita en varios pasajes la versión francesa de "Notas sobre la vida cotidiana en un orden autoritario", de Ximena Barraza, publicada originalmente en una revista del exilio chileno en Madrid.

La hipótesis de Barraza es que la efectividad del orden autoritario radica en la omnipresencia de la violencia. Se trata por un lado de la violencia física, peor por otro de la incertidumbre que provoca que nadie este a salvo de la misma más allá de su conducta. La estrategia autoritaria busca con ello generar conformismo, ya que el conformismo supone que el individuo reprima lo propio, sus intereses, su voluntad de comprometerse, supone que el individuo ponga entre paréntesis y en suspenso parte de sí mismo. El conformista "vive en un estado latente y desinteresado", pero ese desinterés podría ser una barrera psicológica para evitar heridas mayores, el dolor que produce la deprivación de lo propio. La autora
}

según la cual la vida cotidiana durante la dictadura militar será leída a la luz de un terror casi omnipresente, que altera las rutinas y normalidades de la reproducción social y que afecta a la casi totalidad de la población de uno u otro modo.

Muy poco tiempo después, en un artículo hoy célebre, Guillermo O Donnell intentó discutir algunos aspectos de la vida cotidiana en Argentina entre 1976 y 1980, como anticipo de un libro que se había propuesto escribir sobre el cotidiano en Buenos Aires en los años más duros de la dictadura, empresa que finalmente no concretó (O'DONNELL, 1984). Se trató de un texto que buscó prestar atención a los contextos "micro" de la vida social para, a partir de ellos, intentar trazar sus relaciones con los grandes escenarios de la política y del Estado, en un contexto en el que los modos habituales de investigación se tornaron impracticables.

De tal modo, Guillermo O'Donnell y su esposa Cecilia Galli realizaron lo que denominaron una "proto investigación" sobre el cotidiano en Buenos Aires. Entrevistaron a personas de diversos sectores y actividades a los que no les generaba temor interrogar; observaron instituciones educativas y organizaciones profesionales, leyeron y escucharon los discursos de los personeros del régimen, y formularon preguntas -aprovechando el acento extranjero de Cecilia Galli-a personajes de la calle porteña. La muestra así obtenida no alcanzaba pretensión alguna de representatividad, aunque sin duda constituye en nuestros días un elemento muy útil para la comprensión del período.

La intención de comprender las transformaciones de la vida cotidiana se derivaba de los rasgos que según el politólogo argentino convirtieron al régimen en excepcional: no se trató solo del enorme despliegue de la violencia física sino del propósito de modificar radicalmente las relaciones de autoridad en la sociedad, a través del:

... sistemático, continuado y profundo intento de penetrar capilarmente en la sociedad para también allí, en todos los contextos a que la larga mano de ese gobierno alcanzaba, implantar el ORDEN y la AUTORIDAD; ambos calcados de la visión

propone como hipótesis tentativa "que la actual despolitización no es sino una segunda piel -como una capa protectora- de que se cubre el miedo y la desesperación". Si hasta aquí la perspectiva coincide con la idea de desintegración del lazo social de Corradi, el texto de Barraza presenta una apertura a las posibilidades de la resistencia, ya que afirma que "tal como la vida cotidiana es lo que mejor expresa el orden autoritario en acto, así también las experiencias cotidianas son el germen de lo que podría ser un orden alternativo" (BARRAZA, 1980). 
radicalmente autoritaria, vertical y paternalista con que el propio gobierno -y el régimen que se intentó implantar en sus momentos más triunfales- se concebía a sí mismo (O’DONNELL, 1984, p. 14).

De tal modo, si desde el aparato de estado se despojó a la población de los atributos de la soberanía, en los contextos de la cotidianeidad se buscó llevar adelante un proceso de sometimiento e infantilización, como contracara del reforzamiento de la autoridad de los que tenían "derecho a mandar" en la escuela, el trabajo, la familia o el espacio público. En las esfera micro y macrosocial se buscó la aceptación de la idea de que el mando más despótico estaba hecho para el bien de los que obedecían. El gobierno, sostiene el autor, tuvo considerable éxito en esta empresa, no solo por el sometimiento que obtuvo el régimen, sino por el despliegue de las fuerzas autoritarias en la sociedad. Así, es bien sabido que O'Donnell ha sostenido que el control dictatorial sobre la sociedad sólo se pudo desarrollar por la existencia de una extendida voluntad de autocontrol, a la que definió como:

'una sociedad que se patrulló a sí misma', refiriéndose a un grupo amplio de personas que voluntariamente 'se ocuparon activa y celosamente de ejercer su propio pathos autoritario'. Fueron kapos a los que, asumiendo los valores de su (negado) agresor, muchas veces los vemos yendo más allá de lo que el régimen les demandaba (O’DONNELL, 1984, p. 18).

Una enorme mayoría de los entrevistados en la "proto investigación" de O'Donnell, de muy diversas posiciones sociales y opiniones políticas, contrastaban favorablemente el "orden" vigente en 1979 con el "caos" de los años anteriores a 1976. Aunque muchos entre ellos estaban descontentos con distintos aspectos de la política gubernamental -en particular con las políticas económicas - en la medida que la visión de los sujetos continuaba atrapada en aquel dilema "caos-orden", continuaban considerando aceptables las orientaciones generales del régimen militar. Tras los años de intensa movilización política de los primeros años setenta, muchos estaban predispuestos a lo que la represión y la propaganda dictatorial buscaban: un fuerte viraje hacia la privatización de las vidas, una generalizada aspiración a la reducción de la incertidumbre en la vida diaria y la aceptación del discurso que afirmaba que durante los años precedentes al golpe los patrones de autoridad, en todos los contextos, habían llegado a un punto de intolerable desorden. Por ello, sostiene que la pregunta

acerca de por qué en no pocos sectores y contextos de la sociedad el régimen tuvo éxitos importantes en su vocación autoritaria, podría responderse desplazando buena parte del peso de la explicación a esos violentos, y en no pocos sentidos realmente locos y caóticos años que precedieron al golpe de marzo de 1976. Mi impresión es que esos años hicieron, efectivamente, una importante contribución a lo que pasó después, incluso en este plano micro, socialmente intersticial... (O’DONNELL, 1984, p. 20).

Esa contribución de los años previos al golpe no fue sólo la brutal violencia reaccionaria que engendró, sino aquello que la sociedad autorizó en la búsqueda de algún orden. De modo que en esta perspectiva, es la recuperación de cierta "normalidad" en la vida cotidiana-normalización por la que amplísimos sectores estuvieron dispuestos a pagar el costo de una marcada reducción de la actividad pública y hasta de una renuncia a amplias cuotas de autonomía personalpor contraste con el período anterior, la que marcará el tono de la explicación.

\section{El boom de la memoria y las preguntas por complicidades $y$ víctimas}

Desde mediados de la década de 1990 en Argentina reapareció, tras algunos años de menor visibilidad y en el marco de una reforzada lucha política, el interés público por el pasado dictatorial. En este marco, también se renovó la atención académica respecto al pasado dictatorial. Es posible sostener que las mismas preocupaciones que organizaban las demandas públicas del Movimiento por los Derechos Humanos en aquellos años inspiraban las preguntas que orientaban la indagación académica: se trataba sobre todo de dar cuenta de las complicidades y apoyos sociales al régimen por un lado; y por el otro de dar voz a la experiencia y las memorias de las víctimas. En este contexto, se multiplicaron tanto las publicaciones testimoniales como las que fueron resultado del trabajo propio de las ciencias sociales (LVOVICH y BISQUERT; 2008). ${ }^{3}$

\footnotetext{
3 Entre muchos otros trabajos, se publicó en esos momentos un artículo sobre la cotidianeidad en los centros clandestinos de detención: (DI TELLA, 1999).
} 
Como parte de este clima, en 1998 tuvieron lugar dos investigaciones desarrolladas por estudiantes de la Universidad de Buenos Aires (UBA), que se harían públicas algunos años más tarde.

Una de ellas buscaba reconstruir las experiencias e interpretaciones presentes en la memoria colectiva sobre el golpe de 1976. Se basó en 57 entrevistas realizadas -adoptando la perspectiva biográfica- por estudiantes de la Facultad de Ciencias Sociales de la UBA, en el marco de una materia metodológica, a hombres y mujeres de sectores medios de Buenos Aires. Se analizaron esos relatos de vida, que recuperaban fragmentos de las biografías de las personas, buscando dar cuenta de sus "experiencias, emociones e interpretaciones cotidianas" durante el periodo dictatorial.

Al igual que en la interpretación de $\mathrm{O}^{\prime}$ Donnell, en la perspectiva de estas entrevistas, “... la dicotomía caos orden aparece en el relato colectivo como el emergente que podría sintetizar la reacción de la gente común" en un periodo en el que sintieron amenazadas sus certezas básicas (DABENIGNO et al., 2004, p. 128).

En esta investigación, a variable militancia/ no militancia resulto la categoría más significativa para interpretar la perspectiva de los entrevistados. En general, el advenimiento del golpe militar es rememorado a la luz de una evaluación ampliamente negativa del gobierno de Isabel Peron. La mayor parte de los entrevistados señalan la muerte de Juan D. Perón como el inicio de una etapa caracterizada por la violencia y la corrupción Si la violencia de la lucha política del periodo generaba según el relato de todos los entrevistados sensaciones de miedo e incertidumbre; y también la esfera económica es descripta como fuente de inseguridad; en particular aquellos que no tenían militancia política extendían la noción de inseguridad y desorden a las huelgas y conflictos gremiales. Por ello el golpe militar de 1976 es presentado por los entrevistados "como una salida inevitable y previsible" a una situación política y social insostenible. Aunque casi todos refieren a la existencia de un consenso golpista, la mayoría apelan a un otro genérico ("la sociedad", "la gente") que los distancia o al menos los incluye indiferenciadamente en el compromiso con el consenso social mayoritario. ${ }^{4}$ Probablemente es el extendido repudio a la dictadura

\footnotetext{
4 A diferencia de Brasil, donde se comienza a contar con información consistente proveniente de encuestas de opinión realizadas antes y durante la dictadura (MOTTA, 2014) para el caso de la Argentina casi no contamos con ese tipo de materiales. Una excepción es la encuesta desarrollada a fines de 1976 en la pro-
}

propio del momento en que se realizaron las entrevistas el que explique estos modos de distanciamiento personal respecto al consenso que en su momento logró generar la dictadura.

Sin embargo, pueden advertirse matices en la reconstrucción que realizan los entrevistados según su grado de compromiso político. Aquellos que habían militado en la década de 1970 atribuían el golpe a la fragilidad del sistema político o a la acción de los Estados Unidos, mientras los que no habían militado políticamente utilizaban un vocabulario más cercano a las sensaciones. Para la mayor parte de ellos, el golpe fue recibido con la esperanza de restitución de un orden perdido, para muchos de los militantes, con temor por su propio destino. Mientras los entrevistados que habían militado sostienen haber cuestionado siempre a la dictadura, los que no lo hicieron relatan un desencantamiento: tras el orden aparente, en distintos momentos "descubren" la verdad de las desapariciones. Algunas las condenaban en su totalidad, mientras para otros dentro de este grupo, el problema es que la violencia podía alcanzar a cualquiera. Son muy pocos entre los entrevistados los que reivindican la represión.

Como en los anteriores casos, también en este trabajo se reafirma la centralidad del contraste con la etapa anterior para entender la aceptación social del golpe militar. El tipo de tratamiento de las fuentes orales que se realiza en la investigación parte de unos presupuestos anteriores a la reflexión más sistemática sobre la problemática de la memoria en la Argentina, ya que contra la actual convicción acerca de los modos en que los contextos políticos y culturales modifican profundamente la rememoración, en este texto se considera que "... la no contemporaneidad del relato favoreció la autenticidad de los mismos, en la medida en que las presiones del momento pasado no operaban en el presente" (DABENIGNO et al., 2004, p. 126). En el mismo sentido, se afirma que el efecto facilitador de la distancia temporal sobre el recuerdo se ve reforzado cuando la indagación se focaliza en la trama de la vida diaria, ya que las condiciones de la cotidianeidad que se apoyan firmemente en la memoria resultan poco pasibles de distorsión. Por ello, no existió en esta investigación una consideración acerca del impacto del régimen de memoria de fines de los años noventa sobre la manera en que los sujetos rememoraban sus

vincia de Tucumán, la que - pase a las dificultades para su abordaje, pues el material al que se puede acceder resulta incompletomuestra altos niveles de aceptación del régimen militar, y a la vez mayores porcentajes de adhesión cuanto más alto se ubicaban los entrevistados en la escala social (Cf CRENZEL, 2009/2010). 
propias trayectorias, transcurridas más de dos décadas desde los momentos a los que refieren.

El segundo de los trabajos no llegó a materializarse en un artículo, sino que el conjunto de entrevistas fue publicado en el año 2000 en el marco de un programa de fuentes orales del gobierno de la ciudad de Buenos Aires. (CORBETTA, 2000) Todas las entrevistas tuvieron lugar en 1998 y fueron realizadas por estudiantes de distintas carreras de la Universidad de Buenos Aires. La introducción del trabajo muestra la centralidad que se le otorga a la comprensión del impacto del nivel gubernamental sobre los niveles individual, familiar y asociativo, así como del carácter interactivo de esa relación.

En las entrevistas resultan centrales los relatos sobre la omnipresencia del terror estatal, la ruptura de los lazos solidarios y la indiferencia de gran parte de la sociedad. Muy concentrados sobre los aspectos represivos del régimen, los testimonios presentan un sesgo resultado de la selección del universo de los entrevistados. En efecto, aunque se plantea que el universo lo componen ciudadanos comunes, orientando la mirada “... a las percepciones y las vivencias de individuos que se encontraban insertos en un marco de un estado de terror", ocho de los nueve testimoniantes fueron víctimas directas del terror estatal, o sus familiares o miembros de redes de militancia cristiana orientadas a la defensa de los Derechos Humanos.

Con sus méritos y sus déficits, estos trabajos proveyeron una parte importante del material empírico con el que se construyó, poco después, la interpretación sobre el impacto de la dictadura militar en la vida cotidiana desarrollada en el libro más ambicioso sobre aquel período, escrito por Marcos Novaro y Vicente Palermo (2003). A esas fuentes se suman en el texto declaraciones periodísticas, intervenciones de actores públicos, y otros testimonios cuya datación no siempre se aclara. La hipótesis de estos autores, similar a la de O'Donnell, es que la sociedad argentina, en particular en las grandes ciudades y entre 1976 y 1980 , fue atravesada por acontecimientos extraordinarios que ejercieron una gravitación masiva y confirieron una tonalidad particular a la vida cotidiana. E1 acontecimiento que jugo tal papel no era solo la implantación de un régimen dictatorial y represivo, sino la aplicación de un proyecto de reorganización de la sociedad de arriba hacia abajo por parte de un poder que utilizó el terror de Estado como uno de sus instrumentos fundamentales, aunque no exclusivo, y que "consiguió escindir la vida cotidiana en dos esferas opuestas, el mundo de la seguridad y el mundo del temor" (NOVARO y PALERMO, 2003, p. 124). Sin duda alguna, esta visión matizada contribuye a comprender la escisión profunda que atravesó a la sociedad argentina: mientras para algunos la vida cotidiana resultó signada por el terror y se modificó de manera radical, para otros la dictadura resultó una etapa de recuperación de la tranquilidad, en la cual la vida cotidiana recuperó los rasgos de normalidad propios de las rutinas habituales.

A semejanza de los textos que analizamos más arriba, en este libro también se sostiene que el contraste con el gobierno de Isabel Peron organizó una compartida percepción social que explica que se haya recibido al golpe del 24 de marzo con alivio. Sin embargo, las afirmaciones referidas a que "una parte considerable de la sociedad y de todas las clases vio en la perdida de la democracia un precio no muy elevado a pagar para vivir más tranquilos" y que "amplios sectores consintieron la mano dura ilegal" se sustenta ante todo en los testimonios recogidos en los dos trabajos de estudiantes de la UBA, extendiendo sus conclusiones a contextos geográficos y sociales mucho más amplios que los allí considerados.

En el campo de "la seguridad", afirman Novaro y Palermo, la modalidad de la represión a la vez oficial y clandestina, visible e invisible, favoreció una interpretación que daba por sentado que la violencia desplegada desde el Estado no abarcaría a los sujetos que no se involucraran en actividades políticas, como parte de un proceso de anestesiamiento moral y del despliegue de mecanismos de negación. En contrapartida, en el "mundo del temor" se señala que los sectores populares sufrían desde antes del golpe una desmoralización resultado de la experiencia del fin del tercer gobierno peronista, a lo que se sumó rápidamente la intensificación de la represión, la caída del salario y una general ofensiva patronal.

Aunque, en general, la esfera laboral es la que sufrió transformaciones más profundas en sus rutinas, un aporte importante de este texto es considerar los modos diferenciales en los que el terror de estado impactó en la cotidianeidad del trabajo, en función de las características de cada actividad. En los rubros laborales en que la producción es básicamente material, el terror afectó a las personas y al entorno laboral más que al trabajo en sí. Por ello, en estos casos el silencio resultó una estrategia de supervivencia. Donde se trabajaba con intercambios simbólicos, en cambio, la actividad misma fue atravesada por el terror, situaciones que los autores ejemplifican con los casos de la docencia y el psicoanálisis. 
Entre los valiosos aportes de este texto para pensar la problemática que estamos considerando se debe considerar el análisis de los materiales divulgados por los medios de comunicación -que desde la esfera pública impactan sobre la esfera privada y cotidiana, contribuyendo además a brindar los elementos con los que la población decodificaba la situación en que vivía- y los reglamentos y materiales escolares con los que muestran los cambios autoritarios en el sistema educativos. En contraste, el uso de testimonios anónimos y no siempre datados debilita en parte la argumentación, ya que impide un análisis que considere las variables temporales, sociales y culturales en la formulación de sus memorias y argumentaciones.

\section{Vida cotidiana y clases medias}

Dos ambiciosos textos han buscado analizar la vida cotidiana de las clases medias, uno en el período dictatorial y otro abarcando ese tiempo e incluyéndolo en una historia de más largo plazo de la década de 1970. El primero de ellos, Dictadura, vida cotidiana y clases medias. Una sociedad fracturada, fue escrito por la comunicadora social Mariana Caviglia, y el segundo, Los años setenta de la gente común. La naturalización de la violencia, por el sociólogo Sebastián Carassai.

La investigación de Caviglia se centra en la vida cotidiana y se propone explorar cuáles fueron y como se construyeron las condiciones y continuidades socioculturales que hicieron posible la implantación de la dictadura (CAVIGLIA, 2006, p. 27). El texto se basa en el trabajo de la memoria de hombres y mujeres de sectores medios de la ciudad de La Plata que en 1970 tenían entre 15 y 40 años y no participaban de una organización armada ni formaban parte del dispositivo del terror estatal. El interés de la autora es develar "la fractura por la que se precipitó el golpe militar", dar cuenta de las condiciones sociales que hicieron posible su surgimiento: la trama invisible formada por las "ideas corrientes y cotidianas". El trabajo busca "aportar datos e interpretaciones sobre ese régimen de terror que la dictadura instaló de los cuales la historia no puede proveernos -pues cualquier explicación histórica resultaría, por si sola, insuficiente- para mirar y pensar las contradicciones, el conflicto..." (CAVIGLIA, 2006, p. 31). Propone entonces formular las preguntas en el ámbito de la vida cotidiana, espacio en que busca analizar las representaciones, creencias, pasiones, discursos, imaginarios y acciones, es decir, las respuestas de los sujetos a esa situación límite a la cual los enfrento la dictadura.

Aunque interesada en la reconstrucción del pasado y provista incluso de un arsenal teórico adecuado, la autora elige desechar los instrumentos que le ofrece la disciplina histórica, insistiendo en que la revisión de la época de la dictadura y los años previos no constituye "un análisis histórico" pues se topa con la problemática de la memoria, "... que se define por su diferencia con la historia" (CAVIGLIA, 2006, p. 33). A nuestro entender es este presupuesto metodológico el que provoca los principales problemas del texto, ya que la autora renuncia en la práctica a contextualizar adecuadamente las narraciones de la memoria, y a comprender los efectos de los marcos memorialísticos posteriores sobre las prácticas de rememoración, en definitiva, a lograr desglosar los niveles temporales y de sentido que involucra el testimonio, entendido como un discurso del presente sobre el pasado, y por ello sujeto a las condiciones de enunciación del tiempo en que son formulados. Aunque la autora señala que no busca en su obra indagar en documentos históricos y estadísticas "... ni de demostrar la existencia efectiva de los acontecimientos que se narran tal como se los narra" ya que su interés se centra en el punto de vista de los testigos sobre la experiencia del horror, no advierte por completo las implicancias temporales de su elección metodológica.

El libro se estructura en torno al análisis de una larga serie de entrevistas, en las que resulta un denominador común el compartido señalamiento de que la violencia resultó muy anterior al 24 de marzo de 1976. Sin embargo, ese diagnóstico compartido permite a los entrevistados otorgar explicaciones muy diversas al origen de la violencia, con las que significarán también los sentidos atribuidos a la dictadura. Estas distinciones permiten agrupar a los entrevistados en tres categorías: los afines al régimen, los testigos de una lucha que consideraban ajena y los partidarios de las orientaciones de izquierda. Sin embargo, y pese a que las experiencias y perspectivas narradas resultan muy diferentes, el horror resulta una constante tanto en las narraciones cuanto en el esquema intelectivo de la autora, que en ocasiones fuerza la interpretación para tornar omnipresente el horror y sus efectos transformadores sobre la vida cotidiana.

El libro de Carassai discute la extendida idea acerca del viraje de las clases medias hacia la izquierda en lo ideológico y el peronismo en lo político en los años setenta, afirmando la hipótesis contraria, ya que sostiene que, por fuera de grupos de la juventud 
universitaria, la clase media no se radicalizó y mantuvo su antiperonismo. Es notable que, aunque el título de la obra hace referencia a la búsqueda de captar la experiencia histórica de la "gente común", en realidad el trabajo aborda en particular trayectorias propias de las clases medias, comparando casos de grandes ciudades y de pequeñas localidades del interior.

En lo que hace específicamente al período de la dictadura militar, el autor propone como hipótesis que un marco de percepción compartido contribuyó a normalizar la etapa para las clases medias. En esta perspectiva, sostiene que las clases medias compartieron una superstición civil por la que atribuyeron al Estado y sus agentes un saber ilimitado. Esta superstición civil ofreció a las clases media una idea de normalidad: el Estado sabe y la represión no cae en cualquier lado. Sin embargo, en la propia obra hay testimonios contradictorios con esta idea en los que aparece el miedo.

Al igual que en el caso de la obra anteriormente considerada, observamos en este texto dos problemas metodológicos nodales: no tomar en cuenta la ya larga tradición de la historia social y cultural para analizar el período, y considerar al testimonio como un vehículo diáfano para acceder a las ideas y representaciones que los entrevistados tenían en el pasado. ${ }^{5}$ A ello se suma un tercer problema: las clases medias son consideradas aquí un grupo homogéneo, sin que se aproveche adecuadamente el marco comparativo que la elección de distintas localidades del país ofrece para dar cuenta de diversidades regionales, ni introducir otras variables que permitan matizar una mirada excesivamente uniforme.

Por estos comunes problemas, consideramos que ambos textos, aunque resultan innovadores en sus preguntas, no lograron afirmar una visión sólida y sostenida en evidencia empírica acerca de la historia de la vida cotidiana en dictadura, capaz de inaugurar sendas investigativas renovadas.

\section{Nuevas perspectivas, nuevas preguntas}

Algunos trabajos recientes ofrecen, aunque de modo incipiente, perspectivas que, sin dejar de considerar los efectos del terror sobre las subjetividades, prefieren transitar por caminos que rompe con las visiones dicotómicas en las que las únicas opciones disponibles son el apoyo o la resistencia a la dictadura militar. Ello

\footnotetext{
Para una crítica sistemática de esta obra ver CRENZEL, 2013.
}

es probablemente, resultado de una serie de factores que posibilitaron la formulación de nuevas preguntas -no ceñidas estrictamente a la dicotomía consenso/ resistencia- entre los que debemos considerar, más allá de la renovación historiográfica y generacional, un escenario en que los principales responsables del despliegue del terrorismo de estado fueron juzgados y encarcelados. Habiendo sido las demandas de justicia más acuciantes resueltas, las miradas renovadas y atentas a factores no ceñidos estrictamente a la esfera política comenzaron a emerger

Tomamos como ilustración de este proceso dos trabajos. En su investigación sobre la experiencia judía durante la dictadura militar, Emmanuel Kahan señala que, junto al alto número de víctimas de la dictadura militar de dicho origen y a las acusaciones de antisemitismo que recibió el gobierno militar, no se pueden dejar de consignar las dimensiones de normalidad y florecimiento de muchas instituciones israelitas, características que no solo son advertidas por el historiador sino que habían sido destacadas por los actores del período (KAHAN, 2014). No se trataba ello de una manifestación de adhesión ni conformismo, sino de la constatación de que existieron espacios -que incluso albergaron iniciativas culturales alternativasque se desarrollaron más allá de las referencias a la adhesión o la oposición a las políticas estatales. Por su lado, Eleonora Bretal ha cotejado las muy distintas percepciones sobre el pasado dictatorial de trabajadores industriales con pasados militantes en la izquierda y de aquellos que "no estaban metidos en nada", destacándose que para estos, el establecimiento de la dictadura no significó un corte significativo, con lo que la violencia estatal y los procesos de disciplinamiento pudieron no haber significado cambios sustanciales en ciertas dimensiones de su experiencia cotidiana en los lugares de trabajo y de residencia. Algunos de estos ex-obreros explicaron su postura de no estar metidos en nada a partir de valores propios de la cultura del trabajo como el esfuerzo, la dedicación en las actividades laborales diarias, $\mathrm{u}$ obtener el sustento familiar con el dinero resultado de la labor cotidiana, mientras mostraron como opuestos a los valores de la cultura del trabajo el activismo político y/o gremial. Esta modalidad de economía moral de este grupo de trabajadores resulta una explicación que se aleja de interpretaciones centradas puramente en la esfera de las afinidades y enfrentamientos exclusivamente políticos (BRETAL, 2014).

La referencia a estos dos trabajos nos releva de realizar una enumeración exhaustiva de investigaciones 
en desarrollo de autoría de jóvenes investigadores, que muestran que las rutinas de diversas organizaciones y entidades no fueron radicalmente alteradas por la dictadura. Preferimos en cambio presentar, a modo de conclusión, sus denominadores comunes.

El primero es fundamental para una comprensión apropiada del período, y como crítica a buena parte de la bibliografía que hemos recorrido. Se deben evitar las generalizaciones abusivas e indemostrables. La dictadura militar implicó rupturas, represión y experiencias traumáticas, pero no para toda la población. Por ello no toda la población vivió invariablemente aterrorizada, ni se sintió invariablemente amenazada por el poder militar. Sin esa comprensión, resulta imposible avanzar en este campo de la investigación histórica. Por ello, mientras la vida cotidiana de segmentos de la población se desarrolló bajo el signo del terror, para otros la normalidad fue la pauta.

En segundo término, y en un sentido similar, aunque resulta imposible no preguntarse por la politicidad de las acciones, se debe evitar el abuso imperialista de la pregunta por la resistencia o la complicidad. Considerar el peso de las rutinas, la indiferencia, las representaciones de larga data no ligadas de un modo lineal a la política, resulta entonces indispensable para comprender la dimensión de la cotidianidad.

Por último, entendemos que la comprensión de la dimensión cotidiana de la historia de la dictadura militar no resulta posible sin la apelación a los estudios de largo plazo, comparando ese período con otros anteriores para dar cuenta de su especificidad y dando cuenta también de las continuidades. Quizás partiendo de estas premisas podamos avanzar en una historia de la vida cotidiana en dictadura que logre, en efecto, dar cuenta acertadamente de las expresiones moleculares, locales y cotidianas de la dominación, y de los modos en que los actores percibieron estos procesos.

\section{Referencias}

BARRAZA, Ximena. Notas sobre la vida cotidiana en un orden autoritario. In: Araucaria de Chile, n. 11, 1980. Asesado en: 05 julio 2016. http://www.memoriachilena.cl/archivos2/pdfs/ MC0005463.pdf

BRETAL, Eleonora. Rasgos de la cotidianeidad en la 'época de los militares': representaciones de ex-obreros que no estaban metidos en nada. In: Actas de las VII Jornadas de Trabajo sobre Trabajo Reciente, Facultad de Humanidades y Ciencias de la Educación. Universidad Nacional de La Plata, 7 y 8 de agosto de 2014. Asesado en: 05 julio 2016. http://historiapolitica.com/datos/biblioteca/ dictaduraactitudes_bretal.pdf
BROSZAT, Martin et al. Bayern in der NS-Zeit. Munich-Viena: Oldenbourg, 1977-1983. $6 \mathrm{v}$.

BURKE, Peter. Obertura. La nueva historia, su pasado y su futuro. In: BURKE, Peter (Comp.). Formas de hacer Historia. Madrid: Ed. Alianza Universidad, 1996.

CARASSAI, Sebastián. Los años setenta de la gente común. La naturalización de la violencia. Buenos Aires: Siglo XXI, 2013.

CAVIGLIA; Mariana. Dictadura, vida cotidiana y clases medias. Una sociedad fracturada. Buenos Aires: Prometeo, 2006.

CORBETTA, Silvina (Coord.). Un embate contra el olvido. testimonio sobre el impacto del terrorismo de estado en la vida cotidiana. Programa para la creación de fuentes orales. Proyecto Instituto de la Memoria "Nunca Más". Gobierno de la Ciudad de Buenos Aires, 2000.

CORRADI, Juan, El método de destrucción. El terror en la Argentina. In: QUIROGA, Hugo; TCACH, Cesar (Comp.). A veinte años del golpe. Con memoria democrática. Rosario: Homo Sapiens, 1996. p. 89.

CRENZEL, Emilio Sebastián Carassai. Los años setenta de la gente común. La naturalización de la violencia. Buenos Aires: Siglo XXI, 2013. p. 329. In: Nuevo Mundo Mundos Nuevos. Asesado en: 05 julio 2016. http://nuevomundo.revues.org/66159

Una encuesta de opinión pública en Tucumán bajo la dictadura, Una aproximación indicial. In: Telar, Revista del Instituto Interdisciplinario de Estudios Latinoamericanos, Tucumán, año VI, n. 7-8, 2009/2010.

DABENIGNO, Valeria et al. Hacer memoria. Recordando el golpe militar de 1976. In: SAUTU, Ruth (Comp.). El método biográfico. La reconstrucción de la sociedad a partir del testimonio de los actores. Buenos Aires: Lumiere, 2004.

DE CERTEAU, Michel. La invención de lo cotidiano. I . Artes de Hacer. México: Universidad Iberoamericana, 2000.

DI TELLA, Andrés, La vida privada en los campos de concentración. In: DEVOTO, Fernando; MADERO, Marta (Comp.). Historia de la vida privada en la Argentina. Buenos Aires: Taurus, 1999. Tomo III.

ELEY, Geoff. Labor History, Social History, Alltagsgeschichte: Experience, Culture, and the Politics of the Everyday -a New Direction for German Social History? In: Journal of Modern History, v. 61, 1989.

FILC, Judith. Entre el parentesco y la política. Familia y dictadura, 1976-1983. Buenos Aires: Biblos, 1997.

HELLER, Agnes. Sociología de la vida cotidiana. Barcelona: Península, 1987.

KAHAN Emmanuel. Recuerdos que mienten un poco. Vida y memoria de la experiencia judía durante la última dictadura militar. Buenos Aires: Prometeo, 2014.

KERSHAW, Ian. La dictadura nazi. Problemas y perspectivas de investigación. Buenos Aires: Siglo XXI, 2004.

LECHNER, Norbert. Estudiar la vida cotidiana In: Los patios interiores de la democracia. Santiago de Chile: FCE, 1988.

LÜDTKE, Alf. De los héroes de la resistencia a los coautores. 'Alltagsgeschichte' en Alemania. In: CASTELLS, Luis (Ed.). La historia de la vida cotidiana. Madrid: Marcial Pons, 1995. 
LVOVICH; Daniel; BISQUERT, Jaquelina. La cambiante memoria de la dictadura militar desde 1984: Discursos públicos, movimientos sociales y legitimidad democrática. Buenos Aires: UNGS/Biblioteca Nacional, 2008.

MOTTA, Rodrigo Patto Sá. O golpe de 1964 e a ditadura nas pesquisas de opinião. In: Tempo, v. 20, 2014.

NIETHAMMER, Lutz (Dir.). Lebensgeschichte und Sozialkultur im Ruhrgebiet 1930 bis 1960. Berlin-Bonn: J.H.W. Dietz, 1983$1985.3 \mathrm{v}$.

NOLAN, Mary. The Historikerstreit and Social History. In: New German Critique, Special Issue on the Historikerstreit, v. 44, 1988.

NOVARO, Marcos; PALERMO, Vicente. La dictadura militar (1976-1983). Del golpe de estado a la restauración democrática. Buenos Aires: Paidós, 2003.

O'DONNELL, Guillermo. Democracia en la Argentina. Micro y macro. In: OSZLAK, Oscar (Comp.). “Proceso”, crisis y transición democrática/1. Buenos Aires: Centro Editor de América Latina, 1984.

PASSERINI, Luisa. Fascism in Popular Memory. The Cultural experience of the Turin Working Class. Londres y París: Cambridge University Press y Editions de la Maison des Sciences del'Homme, 1987.

SAZ Ismael. Entre la hostilidad y el consentimiento. Valencia en la posguerra. In: Fascismo y franquismo. Valencia: Universitat de Valencia, 2004.

WALTON, John. Aproximaciones a la historia de la vida cotidiana en Inglaterra: 1850-1940. In: CASTELLS, Luis (Ed.). La historia de la vida cotidiana. Madrid: Marcial Pons, 1995.

Recebido: 06 de agosto de 2016 Aprovado: 05 de octubre de 2016

\section{Autor/Author:}

DANIEL Lvovich dlvovich@ungs.edu.ar

- Investigador de la Universidad Nacional de General Sarmiento y del Consejo Nacional de Investigaciones Científicas y Técnicas de la Argentina. Doctor en Historia por la Universidad Nacional de La Plata, su área de especialización es la historia social y política contemporánea.

Pesquisador da Universidad Nacional de General Sarmiento e do Consejo Nacional de Investigaciones Científicas y Técnicas de la Argentina. Doutor em Historia pela Universidad Nacional de La Plata, sua área de especialização é a historia social e política contemporânea

Researcher at the Universidad Nacional de General Sarmiento and of the Consejo Nacional de Investigaciones Científicas y Técnicas de la Argentina. PhD in Historia from the Universidad Nacional de La Plata, his main research area is the social and political contemporary History. 